\title{
Effect of diet fermentability and unsaturated fatty acid concentration on recovery from diet-induced milk fat depression
}

\author{
D. E. Rico, ${ }^{* 1}$ A. W. Holloway, $\dagger$ and K. J. Harvatine ${ }^{\star 2}$ \\ *Department of Animal Science, Penn State University, University Park 16802 \\ †Elanco Animal Health, 2500 Innovation Way, Greenfield IN 46140
}

\begin{abstract}
Diet-induced milk fat depression is caused by highly fermentable and high-unsaturated fatty acid (FA) diets, and results in reduced milk fat concentration and yield, reduced de novo FA, and increased trans isomers of the alternate biohydrogenation pathways. The hypothesis of the current experiment was that a diet higher in fermentability and lower in unsaturated FA (UFA) would accelerate recovery compared with a high-UFA and lower-fermentability diet. Eight ruminally cannulated and 9 noncannulated multiparous Holstein cows were randomly assigned to treatment sequences in a replicated Latin square design. During each period milk fat depression was induced for $10 \mathrm{~d}$ by feeding a low-fiber, high-UFA diet $[25.9 \%$ neutral detergent fiber (NDF) and 3.3\% C18:2]. Following the induction phase, cows were switched to recovery treatments for $18 \mathrm{~d}$ designed to correct dietary fermentability, UFA, or both fermentability and UFA concentration. Treatments during recovery were (1) correction of fiber and UFA diet [control; $31.8 \% \mathrm{NDF}$ and 1.65\% C18:2], (2) a diet predominantly correcting fiber, but not UFA [high oil (HO); $31.3 \% \mathrm{NDF}$ and 2.99\% C18:2], and (3) a diet predominantly correcting UFA, but not fiber concentration [low fiber (LF); 28.4\% NDF and 1.71\% C18:2]. Milk and milk component yield, milk FA profile, ruminal $\mathrm{pH}$, and 11 rumen microbial taxa were measured every third day during recovery. Milk yield decreased progressively in $\mathrm{HO}$ and control, whereas it was maintained in the LF diet. Milk fat concentration increased progressively during recovery in all treatments, but was on average $9 \%$ lower in LF than control from d 12 to 18 . Milk fat yield increased progressively in all treatments and was not different between control and LF at any time
\end{abstract}

\footnotetext{
Received October 17, 2014.

Accepted June 9, 2015.

${ }^{1}$ Current address: Department of Animal Science, Université Laval, Québec, QC, Canada.

${ }^{2}$ Corresponding author: kjh182@psu.edu
}

point, but was lower in HO than control on d 15. Milk trans-10 C18:1 and trans-10,cis-12 conjugated linoleic acid decreased progressively in all treatments, but was higher in HO than control from d 3 to 18 [136 \pm 50 and $188 \pm 57 \%$ (mean $\pm \mathrm{SD})]$, whereas LF caused a smaller increase in these FA compared with control $(67 \pm 25$ and $90 \pm 22 \%)$. Additionally, milk trans-11 C18:1 and cis-9,trans-11 conjugated linoleic acid was decreased in control and LF and increased in HO during recovery. Selected microbial species observed changed during recovery, but major treatment differences were only observed for Streptococcus bovis. The LF diet that was similar in UFA but $3.4 \%$ units lower in NDF compared with to the control had a similar decrease in alternate trans biohydrogenation intermediates in milk. The $\mathrm{HO}$ diet that was similar in NDF but $2.0 \%$ units higher in UFA compared with the control had higher alternate trans biohydrogenation intermediates in milk compared with control. However, recovery of milk fat yield was similar between treatments at most time points.

Key words: milk fat depression, dairy cow, conjugated linoleic acid

\section{INTRODUCTION}

Milk fat is the most variable milk component on farms and is especially responsive to nutritional factors. Classical diet-induced milk fat depression (MFD) is a specific reduction in milk fat concentration and yield commonly observed when dairy cows are fed highly fermentable and high-unsaturated fatty acid (UFA) diets (Bauman and Griinari, 2001). Specific trans FA, such as trans-10,cis-12 CLA, formed as intermediates during altered ruminal biohydrogenation of linoleic acid have been identified as the causative factors of diet-induced MFD (Harvatine et al., 2009). The alternate biohydrogenation $(\mathbf{B H})$ pathway results from a change in rumen environment, altered rumen microbial population, or a large amount of UFA requiring $\mathrm{BH}$ (Lourenço et al., 2010; Weimer et al., 2010). Diet-induced MFD has been extensively studied (reviewed by Harvatine et al., 2009); however, recovery from MFD and mechanisms to accelerate recovery have only recently been investigated 
Table 1. Example treatment sequences in the $3 \times 3$ Latin square design investigating the effect of dietary fiber and unsaturated fatty acid (UFA) concentration on recovery from milk fat depression ${ }^{1}$

\begin{tabular}{|c|c|c|c|c|c|}
\hline $\begin{array}{l}\text { Treatment } \\
\text { sequence }\end{array}$ & $\begin{array}{l}\text { Period 1, } \\
10 / 18 \mathrm{~d}\end{array}$ & $\begin{array}{l}\text { Washout, } \\
7 \mathrm{~d}\end{array}$ & $\begin{array}{l}\text { Period 2, } \\
10 / 18 d\end{array}$ & $\begin{array}{l}\text { Washout, } \\
7 \mathrm{~d}\end{array}$ & $\begin{array}{l}\text { Period } 3 \\
10 / 18 \mathrm{~d}\end{array}$ \\
\hline 1 & MFD/Control & Control & $\mathrm{MFD} / \mathrm{LF}$ & Control & $\mathrm{MFD} / \mathrm{HO}$ \\
\hline 2 & MFD/HO & Control & MFD/Control & Control & $\mathrm{MFD} / \mathrm{LF}$ \\
\hline 3 & $\mathrm{MFD} / \mathrm{LF}$ & Control & $\mathrm{MFD} / \mathrm{HO}$ & Control & MFD/Control \\
\hline
\end{tabular}

${ }^{1}$ Milk fat depression (MFD) was achieved by feeding the induction diet (low fiber, high UFA) during the first $10 \mathrm{~d}$ of each period. Treatments were a high fiber, low UFA diet (control), a diet correcting UFA, but not fiber level (Low fiber: LF), and a diet correcting fiber, but not UFA (high oil: HO) fed for $18 \mathrm{~d}$ during the recovery phase. Monensin was fed in all diets.

(Rico and Harvatine, 2013; Rico et al., 2014a,b). The current experiment uses a similar experimental model to investigate recovery from MFD.

Dietary starch, fiber, and UFA concentration, rate of fermentation, and monensin are some of the risk factors for MFD. Monensin is commonly fed to dairy cows to increase feed efficiency; however, it has been associated with lower milk fat concentration concomitantly with increased milk trans FA, including trans-10 C18:1 and trans-10,cis-12 CLA, and reduced concentration of de novo synthesized FA in milk (Duffield et al., 2008). In addition, monensin supplementation in high-UFA diets increased the concentration of intermediates of the alternate $\mathrm{BH}$ pathway in rumen fluid and milk (AlZahal et al., 2008; He et al., 2012). The current experiment was conducted with monensin in all diets.

We recently reported the time course of the induction of and recovery from classical diet-induced MFD (Rico and Harvatine, 2013). Briefly, MFD was induced to near maximal levels in $9 \mathrm{~d}$ by feeding a low-fiber and high-UFA diet (29.5\% NDF, 27\% starch, and 3.4\% C18:2). After correction of both dietary fiber and UFA concentration $(36.9 \%$ NDF, $18 \%$ starch, and $1.6 \%$ C18:2), recovery from MFD occurred progressively, as milk fat yield was not different from control on d 11 and was completely recovered by d 19 (Rico and Harvatine, 2013). This correction of both dietary fiber and UFA concentration represents a near best-case scenario for recovery of milk fat, but results in a substantial decrease in diet energy density and risks loss of milk yield.

The objective of the current study was to investigate the effect of dietary NDF and UFA concentration on the time course of recovery of milk fat synthesis and reestablishment of normal rumen $\mathrm{FA} \mathrm{BH}$ pathways and microbial populations in diets supplemented with monensin. We hypothesized that increasing fermentability (3.4\% unit lower NDF) with a similar UFA concentration compared with the control would accelerate recovery of normal rumen $\mathrm{BH}$ more than a diet with similar fermentability but higher UFA (2.0\% units) compared with the control. This is expected because diet ferment- ability can alter rumen microbial populations, whereas UFA are the substrates for formation of trans FA and also modify rumen microbial populations.

\section{MATERIALS AND METHODS}

\section{Experimental Design and Treatments}

The experiment was conducted from August to November of 2011. All experimental procedures were approved by the Pennsylvania State University Institutional Animal Care and Use Committee. Eight ruminally cannulated and 9 noncannulated multiparous Holstein cows $(127 \pm 37 \mathrm{~d}$ postpartum; mean $\pm \mathrm{SD})$ were randomly assigned to 1 of 6 treatment sequences in a Latin square design (example sequences in Table 1). Cows were housed in a tiestall barn located at the Pennsylvania State University Dairy Production Research and Teaching Center.

Each period was divided into a 10-d induction phase and an 18-d recovery phase (Table 1). During each period, short-term MFD was first induced by feeding a low-fiber, high-UFA diet (induction; $25.9 \%$ NDF, $7.1 \%$ FA, and 3.3\% C18:2; Table 2). The recovery treatments that followed were a diet correcting dietary fiber and UFA (control; $31.8 \%$ NDF, $4.2 \%$ FA, and 1.65\% C18:2); a diet correcting fiber, but not UFA [high oil (HO); $31.5 \% \mathrm{NDF}, 6.6 \% \mathrm{FA}$, and $2.99 \% \mathrm{C} 18: 2]$; and a diet correcting UFA, but not fiber level [low fiber (LF); $28.4 \% \mathrm{NDF}, 4.3 \% \mathrm{FA}$, and $1.71 \% \mathrm{C} 18: 2]$. The HO represents higher UFA and LF represents lower fiber relative to the control, respectively. Cows were fed the control diet during a 7-d washout between periods. The combination of the washout and induction provided 17 $\mathrm{d}$ between experimental diets and minimized the possibility of carry-over between experimental diets. Monensin (Rumensin 90; Elanco Animal Health, Greenfield, IN) was top-dressed to all cows at a rate of $450 \mathrm{mg} /$ cow per day in $1.0 \mathrm{~kg}$ (DM basis) of cookie meal for the duration of the experiment. All cows received bST (Posilac; Elanco Animal Health) every 14 d. 
Table 2. Ingredient and chemical composition of experimental diets

\begin{tabular}{|c|c|c|c|c|}
\hline \multirow[b]{2}{*}{ Item } & \multicolumn{4}{|c|}{$\operatorname{Diet}^{1}$} \\
\hline & Induction & Control & $\mathrm{HO}$ & LF \\
\hline \multicolumn{5}{|l|}{ Ingredient, $\%$ of DM } \\
\hline Corn silage ${ }^{2}$ & 36.3 & 41.1 & 39.9 & 35.8 \\
\hline Alfalfa haylage $^{3}$ & 7.7 & 18.5 & 19.3 & 15.6 \\
\hline Canola meal & 11.2 & 11.1 & 10.5 & 10.6 \\
\hline Ground corn & 18.9 & 6.6 & 3.9 & 15.3 \\
\hline Roasted soybeans & 7.5 & - & 7.8 & - \\
\hline Expeller soybean meal ${ }^{4}$ & 0.8 & 8.8 & 2.6 & 6.7 \\
\hline Cottonseed hulls & 3.5 & 3.8 & 4.8 & 4.1 \\
\hline Cookie meal & 4.6 & 1.9 & 1.8 & 4.3 \\
\hline Grass hay/straw ${ }^{5}$ & 3.1 & 3.1 & 3.1 & 2.6 \\
\hline Minerals and vitamins $\operatorname{mix}^{6}$ & 2.4 & 3.0 & 2.8 & 3.0 \\
\hline Sugar cane molasses & 2.1 & 1.5 & 1.4 & 1.4 \\
\hline Soybean oil & 1.6 & - & 1.5 & - \\
\hline Optigen $^{7}$ & 0.4 & 0.5 & 0.5 & 0.5 \\
\hline \multicolumn{5}{|l|}{ Nutrient. ${ }^{8} \%$ of DM } \\
\hline $\mathrm{CP}$ & 16.3 & 19.2 & 19.0 & 18.0 \\
\hline NDF & 25.9 & 31.8 & 31.3 & 28.4 \\
\hline Forage NDF & 16.6 & 22.5 & 22.4 & 19.3 \\
\hline $\mathrm{ADF}$ & 16.3 & 21.6 & 21.6 & 19.0 \\
\hline Starch & 31.3 & 24.0 & 21.6 & 29.0 \\
\hline FA & 7.1 & 4.2 & 6.6 & 4.3 \\
\hline C18:1n-9 & 1.53 & 0.85 & 1.31 & 0.92 \\
\hline $\mathrm{C} 18: 2 \mathrm{n}-6$ & 3.30 & 1.65 & 2.99 & 1.71 \\
\hline C18:3n-3 & 0.42 & 0.29 & 0.49 & 0.26 \\
\hline Mean particle size,${ }^{9} \mathrm{~mm}$ & 4.32 & 3.81 & 4.19 & 3.81 \\
\hline
\end{tabular}

${ }^{1}$ Induction is a low-fiber and high-unsaturated fatty acid (UFA) diet fed during the induction phase of each period; control is correction of fiber and UFA concentration; high oil (HO) is correction of fiber, but not of UFA concentration; low fiber (LF) is correction of UFA, but not fiber concentration.

${ }^{2}$ Contained $38.5 \%$ DM, $8.1 \%$ CP, $31.1 \%$ NDF, and $17.3 \%$ ADF.

${ }^{3}$ Contained $46.4 \%$ DM, $20.8 \%$ CP, $40.9 \%$ NDF, and $35.4 \%$ ADF

${ }^{4}$ SoyPLUS (West Central Cooperative, Ralston, IA).

${ }^{5}$ Contained $88.9 \%$ DM, $8.6 \% \mathrm{CP}, 68.2 \% \mathrm{NDF}$, and $41.3 \%$ ADF.

${ }^{6}$ Composition (DM basis): $11 \% \mathrm{CP} ; 18 \%$ NDF; $5.2 \%$ fat; $14.9 \% \mathrm{Ca}$; $0.35 \% \mathrm{P} ; 4.58 \% \mathrm{Mg} ; 0.41 \% \mathrm{~K} ; 0.31 \% \mathrm{~S} ; 357 \mathrm{mg} / \mathrm{kg}$ of Cu; $1,085 \mathrm{mg} /$ $\mathrm{kg}$ of Zn; $181 \mathrm{mg} / \mathrm{kg}$ of Fe; $6.67 \mathrm{mg} / \mathrm{kg}$ of Se; 262,105 IU $/ \mathrm{kg}$ of vitamin A (retinyl acetate); $65,421 \mathrm{IU} / \mathrm{kg}$ of vitamin D (activated 7-dehydrocholesterol); and 1,970 IU/kg of vitamin E (DL- $\alpha$ tocopheryl acetate). ${ }^{7}$ Optigen is an NPN source $(256 \% \mathrm{CP}$, DM basis), Alltech Inc. (Lexington, KY).

${ }^{8}$ Analyzed by Cumberland Valley Analytical Services (Maugansville, $\mathrm{MD} ; \mathrm{n}=3$ per diet). Fatty acid profile analyzed by GC-flame ionization detection (full dietary FA profile shown in Supplemental Table S1; http://dx.doi.org/10.3168/jds.2104-8990).

${ }^{9}$ The particle size distribution was analyzed using the Penn State Particle Separator $(\mathrm{n}=2$ per diet). Particles remaining (\% of total) in the upper sieve, middle sieve, lower sieve, and bottom pan were 3 , 27,47 , and 24, respectively, for the induction diet; $3,35,41$, and 22 , respectively, for the control diet; $2,31,45$, and 21 , respectively, for the $\mathrm{HO}$ diet; and $3,28,45$, and 25 , respectively, for the LF diet.

\section{Feed Sampling and Analysis}

Cows were fed individually once daily $(0800 \mathrm{~h})$ at $110 \%$ of expected intake and intake was recorded daily. Forage and base diet DM concentration was determined weekly for diet adjustment and DMI determination (72 $\mathrm{h}$ in a forced-air oven at $55^{\circ} \mathrm{C}$ ). All individual feed ingredients were sampled weekly, composited by period, and analyzed as previously described by Rico et al. (2014a).

\section{Milk Sampling and Analysis}

Cows were milked twice daily at 0500 and $1700 \mathrm{~h}$, and milk yield was determined by an integrated milk meter (AfiMilk; SAE Afikim, Israel). Milk was sampled at both milkings on d 0 (last day of induction phase), 3 , $6,9,12,15$, and 18 of each recovery phase and analyzed as described by Rico et al. (2014a). Briefly, milk fat was analyzed for fat (filter B) and protein by infrared spectroscopy and FA composition (extracted with hexane:isopropanol, transmethylated in the presence of sodium methoxide, and FAME-quantified by gas chromatography with a capillary column and a flame ionization detector; FA identified are reported in Supplemental Table S2; http://dx.doi.org/10.3168/jds.20148990). Under the conditions used, cis-9,trans-11 CLA was expected to elute with other isomers, including trans-7,cis-9 CLA and trans-8,cis-10 CLA; however, cis-9,trans-11 CLA represents the majority of the peak (Fritsche et al., 1999). The milk FA desaturase indexes were calculated as an estimation of the activity of the stearoyl CoA desaturase enzyme [product/(substrate + product)].

\section{Rumen $\mathrm{pH}$ and Microbial Taxa Analysis}

Ruminal $\mathrm{pH}$ was monitored every 5 min for $24 \mathrm{~h}$ on d $0,3,6,9,12,15$, and 18 of each recovery phase in the 8 ruminally cannulated cows using indwelling ruminal $\mathrm{pH}$ probes (Kahne Ltd., Auckland, New Zealand) as described by Ying et al. (2015).

Whole ruminal digesta samples were collected at $1600 \mathrm{~h}$ on $\mathrm{d} 0,3,6,9,12,15$, and 18 of each recovery period. Samples were stored at $-80^{\circ} \mathrm{C}$, freeze-dried (Ultra 35-XL; Virtis Co. Inc., Gardiner, NY) and ground in a coffee grinder (model 80335, Hamilton Beach Brands Inc., Glen Allen, VA) before DNA extraction. The DNA was isolated using a commercial kit (QIAamp DNA stool mini kit, Qiagen, Germantown, MD) with modifications similar to $\mathrm{Yu}$ and Morrison (2004). Briefly, approximately $220 \mathrm{mg}$ of digesta was homogenized for 5 min with $1.2 \mathrm{~mL}$ of lysis buffer and $0.4 \mathrm{~g}$ of $0.1-\mathrm{mm}$ sterile zirconia beads using a benchtop vortex equipped with a Mo Bio Vortex-Genie 2 adapter (Mo Bio laboratories, Carlsbad, CA). After bead-beating, samples were incubated twice at $95^{\circ} \mathrm{C}$ for $15 \mathrm{~min}$ with vortexing every $5 \mathrm{~min}$ and beadbeating between incubations. The DNA concentration was determined by spectroscopy (NanoDrop ND-1000 Spectrophotometer, Nanodrop Technologies, Wilmington, DE). The relative abundance of select microbial 
taxa was determined using real-time quantitative (q) PCR and $400 \mathrm{n} M$ of previously validated primers and conditions (Supplemental Table S3; http://dx.doi. org/10.3168/jds.2014-8990). Reactions were conducted in triplicate (PerfeCTa SYBR Green SuperMix with ROX, Quanta Biosciences, Gaithersburg, MD; Applied Biosystems 7900 HT Fast Real-Time PCR system, Life Technologies, Grand Island, NY). Primer specificity was evaluated by melting curve analysis and efficiency (E) was calculated as $\mathrm{E}=10^{-1 / \mathrm{s}}$, where $\mathrm{s}$ is the slope of standard curve. Abundance of bacteria, protozoa, and fungi are reported as a percent of total bacteria

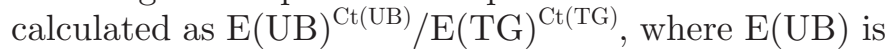
the efficiency of the reaction for the universal bacteria primer set, $\mathrm{E}(\mathrm{TG})$ is the efficiency of the reaction for the target gene, and $\mathrm{Ct}$ is the average cycle threshold value for each sample. Second, abundance of total fungi, protozoa, and bacteria are reported relative to d 0 of control, when animals were fed a common diet.

\section{Statistical Analysis}

Data were analyzed using the MIXED procedure of SAS with repeated measures (version 9.3, SAS Institute Inc., Cary, NC) as described by Rico et al. (2014a). Briefly, the model included the random effect of treatment sequence, period, and cow nested in treatment sequence and the fixed effect of treatment, time (day on recovery), the interaction of treatment and time, and the last day of the induction period as a covariate. The preplanned contrasts were control versus $\mathrm{HO}$ and control versus LF at each time point. Significance and tendencies were declared at $P<0.05$ and $P<0.10$, respectively, for main effects and preplanned contrasts and at $P<0.10$ and $P<0.15$, respectively, for interactions.

Second, a random regression analysis was performed on milk fat concentration and yield and concentration of selected milk FA also as described by Rico et al. (2014a). The model included the random effect of cow and period, and the fixed effect of treatment, linear effect of time, quadratic effect of time, the interaction of treatment and time, and the interaction of treatment and the quadratic effect of time. A reduced model was used which excluded the interaction of treatment by the quadratic effect of time when not significant.

\section{RESULTS}

\section{Induction of MFD}

Average milk fat concentrations at the start and end of each MFD induction phase averaged 3.10 and $2.26 \%$, respectively, and milk fat yields were 1.30 and $1.01 \mathrm{~kg} / \mathrm{d}(\mathrm{SEM}=0.07 \mathrm{~kg} / \mathrm{d})$, respectively (Table 3 ). This represents a 27 and $22 \%$ reduction in milk fat concentration and yield from the start to end of each MFD induction phase. There was no difference in milk fat concentration or yield between treatments at the end of the induction phase of each period or at the end of the washout periods following period 1 and 2 (all $P$ $>0.2$; data not shown), and milk fat concentration and yield did not differ between the last day of the recovery (d 18 or recovery) and the last day of the washout period (d 0 of induction; Table 3). This indicates little carryover effect entering the induction phase. Chemical composition of all diets closely followed expected values (Table 2) and monensin concentration in the premix topdress was $87 \%$ of target value.

\section{DMI and Milk Production and Composition}

A treatment by time interaction was observed for DMI $(P=0.07$; Figure 1a). Dry matter intake sharply decreased in all treatments between $\mathrm{d} 0$ and 1 of the recovery phase and progressively increased thereafter, reaching a plateau on approximately d 7. Dry matter intake was higher in LF than control on 16 of the $18 \mathrm{~d}$

Table 3. Milk yield and composition during the induction phase and end of recovery

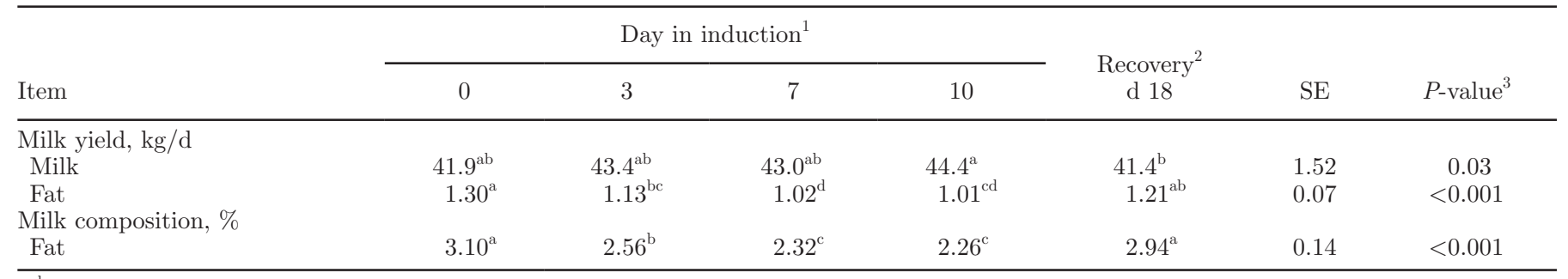

${ }^{\mathrm{a}-\mathrm{d}}$ Treatment means with different superscripts differ $(P<0.05)$ by Tukey's test.

${ }^{1}$ Milk fat depression was induced by feeding a low-fiber and high-unsaturated fat diet. Samples were taken the day before the diet and after 7 and $10 \mathrm{~d}$.

${ }^{2}$ Mean of all treatments on the last day of the recovery period.

${ }^{3}$ Main effect of day. 

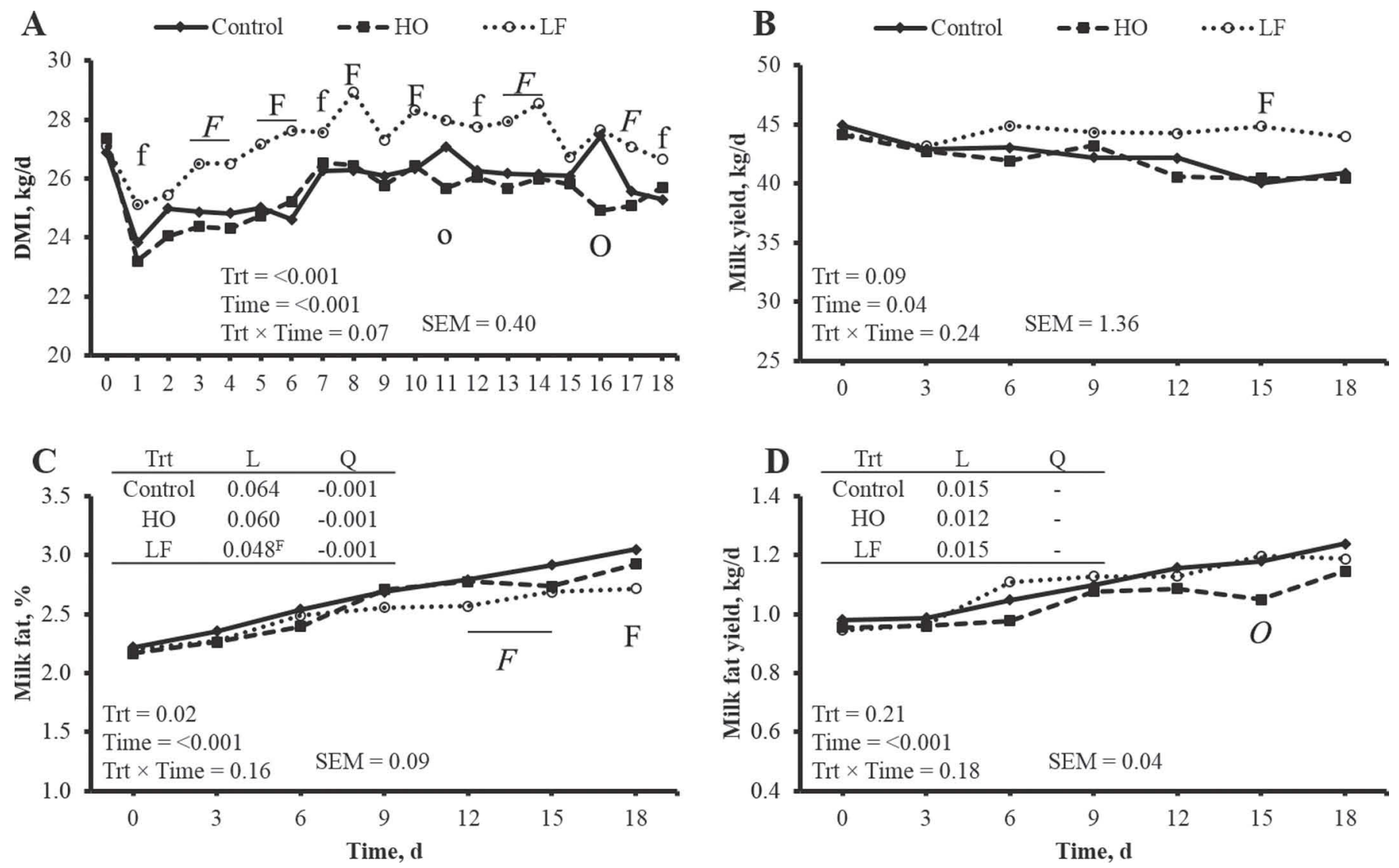

Figure 1. Effect of primarily correcting dietary fiber or unsaturated fatty acid (UFA) concentration on DMI (A), milk yield (B), and milk fat concentration (C) and yield (D) during recovery from milk fat depression. Treatments were a high-fiber, low-UFA diet (control), a diet correcting UFA, but not fiber level (low fiber; LF), and a diet correcting fiber, but not UFA (high oil; HO). Preplanned contrasts tested the difference between control and LF $(\mathrm{F}=P<0.05, F=P<0.01$, and $\mathrm{f}=P<0.1)$ and between control and $\mathrm{HO}(\mathrm{O}=P<0.05, O=P<0.01$, and $\mathrm{o}=$ $P<0.1)$. Significance of treatment (Trt), time, and the interaction of treatment and time are reported within each figure. The insets in $\mathrm{C}$ and D report the slope for the linear (L) and quadratic (Q) coefficients with preplanned contrasts from random regression analysis.

observed and HO was lower than control on d 16 . No treatment by time interaction was noted for milk yield, although on d $15 \mathrm{LF}$ was higher than control $(4.7 \mathrm{~kg} / \mathrm{d}$; $P<0.01)$. An effect of time $(P=0.04)$ and a tendency $(P=0.09)$ for an effect of treatment on milk yield were seen (Figure 1b). Milk yield decreased over time and overall tended to be higher in LF than in control (42.3 vs. $44.2 \mathrm{~kg} / \mathrm{d}$ ).

No treatment by time interactions were observed for milk fat concentration and yield by ANOVA. Milk fat concentration and yield increased progressively in all treatments during the recovery phase (time $=P$ $<0.001$; Figures 1c and d). Overall, milk fat concentration was lower in LF than in control $(P<0.05)$. Specifically, LF decreased $(P=0.02)$ milk fat concentration compared with control from d 12 to 18 by $9.0 \pm 1.8 \%$ (mean $\pm \mathrm{SD}$ ); however, $\mathrm{LF}$ did not affect milk fat yield at any time point. Milk fat concentration and yield were not different between control and HO except on d 15, when HO decreased milk fat yield by $11 \%$ relative to control $(P<0.03)$. By regression analysis, milk fat concentration increased quadratically in all treatments $(P<0.01$; Supplemental Table S4; http://dx.doi.org/10.3168/jds.2014-8990). However, an interaction between treatment and the linear rate of recovery of milk fat concentration was observed (Figure 1 ), as LF decreased the linear rate of recovery of milk fat concentration compared with control $(P<0.01)$. There were no interactions of treatment and rate or recovery of milk fat yield.

An effect of time on milk protein yield was noted ( $P$ $=0.04)$, but no effect of treatment or treatment by time interaction was seen (Supplemental Figure S1; http:// dx.doi.org/10.3168/jds.2014-8990). Compared with control, LF increased milk protein yield by $11 \pm 1.5 \%$ from d 15 to $18(P<0.05)$. However, there was a treatment by time interaction for milk protein concentration $(P<0.05$; Supplemental Figure S1). Concentration of milk protein progressively decreased from d 3 to 18 in all treatments (time effect: $P<0.001$ ); however, from 
d 6 to 18 it was $2.9 \pm 0.6 \%$ higher in $\mathrm{HO}$ than control $(P<0.05)$.

\section{Milk De Novo and Preformed FA}

There was a treatment by time interaction for the yield of milk FA less than 16C (de novo synthesized) and 16C FA $(P<0.001$; Figure 2$)$, as well as for the concentrations of milk de novo, $16 \mathrm{C}$, and greater than 16C (preformed) FA $(P<0.001)$. The concentration of milk de novo FA increased progressively for the control and LF treatments, but was marginally decreased in LF compared with control from d 15 to $18[4.3 \pm 0.38 \%$ (mean $\pm \mathrm{SD}$ ); $P<0.05$; Figure 2a]. Similarly, yield of de novo-synthesized FA progressively increased for both control and LF, but was not different between control and LF at any time point (Figure 2b). In contrast, concentration and yield of de novo-synthesized FA remained relatively constant over time in the $\mathrm{HO}$ treatment, and were decreased compared with control from d 3 to $18(27 \pm 1.2$ and $34 \pm 3.4 \%$ on d 15 and 18 , respectively; $P<0.01]$.

Milk 16C FA concentration approached near maximal values by $\mathrm{d} 3$ in both control and LF, but tended to be higher in LF than control on d 3 and $9(P=0.09)$. However, milk 16C FA remained constant in $\mathrm{HO}$, and was lower than control from d 3 to $18(12 \pm 3.4 \%$; $P<$ 0.001; Figure 2c). Similarly, yield of 16C FA increased progressively in control and $\mathrm{LF}$, and tended $(P<0.1)$ to be lower in LF than control on d 12; however, it remained relatively constant in $\mathrm{HO}$ and was lower than control from d 3 to 18 (21 $\pm 4.5 \%$; $P<0.001$; Figure $2 \mathrm{~d})$.

Concentration of milk preformed FA decreased progressively in control and LF and tended to be lower in LF than control on d 6 and $9(P<0.1$; Figure $2 \mathrm{e})$. In contrast, concentration of milk preformed FA slightly increased initially and then remained nearly constant in $\mathrm{HO}$ and was on average $21 \pm 5.3 \%$ higher than control from d 3 to $18(P<0.01)$. Yield of milk preformed FA remained nearly constant in control and LF, but was higher in HO than in control on d 9 and 18 (16 and $12 \%$, respectively; $P<0.05$; Figure $2 \mathrm{f}$ ).

\section{Milk Trans FA}

There was a treatment by time interaction for the concentration of milk trans-10 and trans-11 C18:1 and trans-10,cis-12 and cis-9,trans-11 CLA $(P<0.01$; Figure 3). Concentration of milk trans-10 C18:1 and trans-10,cis-12 CLA decreased progressively in all treatments (Figure 3a and 3c). However, both FA were greatly increased in $\mathrm{HO}$ compared with control from d
3 to 18 [trans-10 C18:1 increased $140 \pm 50 \%$ and trans10,cis-12 CLA increased $190 \pm 57 \%$ (mean $\pm \mathrm{SD}$ )], whereas in the LF treatment both FA were increased compared with control, but near baseline concentration, from d 9 to 18 (trans-10 C18:1 increased $67 \pm 25 \%$ and trans-10,cis-12 CLA increased $90 \pm 22 \%$ ).

The concentration of milk trans-11 C18:1 decreased modestly over time in control and LF, and was lower in LF relative to control from d 6 to $18(30 \pm 2.7 \%$; Figure 3b). However, HO increased trans-11 C18:1 progressively and was higher than control from d 3 to 18 (96 $\pm 5.5 \%$ from d 15 to 18). Cis-9,trans-11 CLA followed a similar pattern to trans-11 C18:1 (Figure 3d). Briefly, cis-9,trans-11 CLA decreased progressively in both control and LF and did not differ at any time point. In contrast, $\mathrm{HO}$ increased progressively and was higher than control from d 3 to 18 (90 $\pm 3.7 \%$ from d 15 to 18$)$.

\section{Rate of Recovery of FA}

A random regression analysis was used to determine the rate of recovery of selected FA and regression parameters are provided in the supplemental data. Briefly, linear and quadratic interactions with treatment were detected for both the concentration and yield of de novo and 16C FA $(P<0.01$; Supplemental Table S4; http:// dx.doi.org/10.3168/jds.2014-8990). Concentration of de novo and 16C FA increased quadratically during recovery in control and LF; however, HO drastically reduced the linear and increased the quadratic rate of recovery compared with control $(P<0.05)$. Linear and quadratic interactions with treatment were also detected for the recovery of preformed FA concentration $(P<0.001)$, as control and LF decreased quadratically and HO increased quadratically. In contrast, only an interaction between treatment and the linear rate of recovery of preformed FA yield was observed $(P=0.02)$. Yield of preformed FA increased linearly in all treatments $(P<$ $0.001)$, but HO increased the rate by approximately 5 fold compared with control $(P=0.01)$.

Interactions between treatment and the linear and quadratic effects of time were observed for the concentrations of milk trans-10 C18:1 and trans-10,cis-12 CLA $(P<0.001$; Supplemental Table S4; http://dx.doi. org/10.3168/jds.2014-8990). For both FA, the linear rate of decrease was reduced by $\mathrm{HO}$ and LF compared with control. Additionally, control and LF plateaued near d 12, whereas HO continued to decrease through d 18. Interactions between treatment and the linear and quadratic effects of time were also detected for the concentrations of milk trans-11 C18:1 and cis-9,trans-11 CLA $(P<0.05)$. Both FA increased quadratically in 
HO, whereas they decreased quadratically in control and LF. The linear rate of decrease was higher for LF than for control $(P<0.05)$.

A treatment by time interaction was noted for $\mathrm{C} 14$ and C16 desaturase indexes (Supplemental Figure S2; http://dx.doi.org/10.3168/jds.2014-8990). Both indexes modestly decreased over time, but the C14 index was higher in $\mathrm{HO}$ and $\mathrm{LF}$ than control from d 6 to 18.
Similarly, the C16 index was higher in HO than control from d 9 to 18, whereas it was higher in LF than control on d 6 and from d 12 to $18(P<0.05)$.

\section{Ruminal $\mathrm{pH}$}

There was no interaction of treatment and time or overall effect of treatment on rumen average $\mathrm{pH}$ and


Figure 2. Effect of primarily correcting dietary fiber or unsaturated fatty acid (UFA) concentration on the concentration and yield of de novo (A and B), 16C (C and D), and preformed (E and F) FA during recovery from milk fat depression. Treatments were a high-fiber, low-UFA diet (control), a diet correcting UFA, but not fiber level (low fiber; LF), and a diet correcting fiber, but not UFA (high oil; HO). Significance of treatment (Trt), time, and the interaction of treatment and time are reported within each figure. Preplanned contrasts tested the difference between control and LF (F $=P<0.05, F=P<0.01$, and $\mathrm{f}=P<0.1)$ and between control and $\mathrm{HO}(\mathrm{O}=P<0.05$ and $O=P<0.01)$. 
A

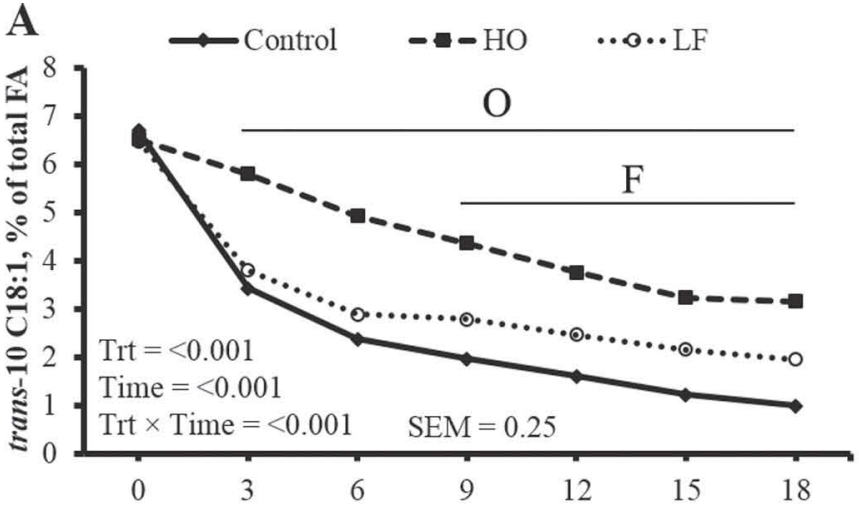

C

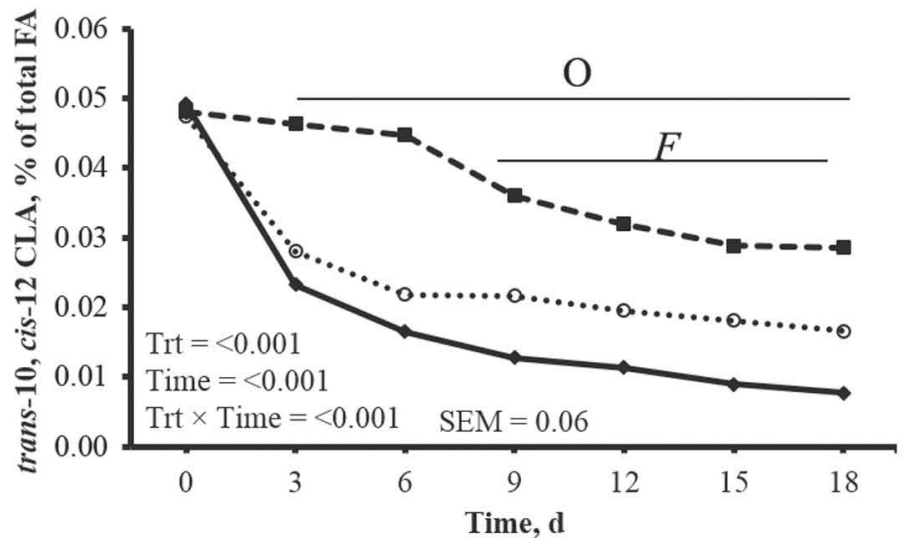

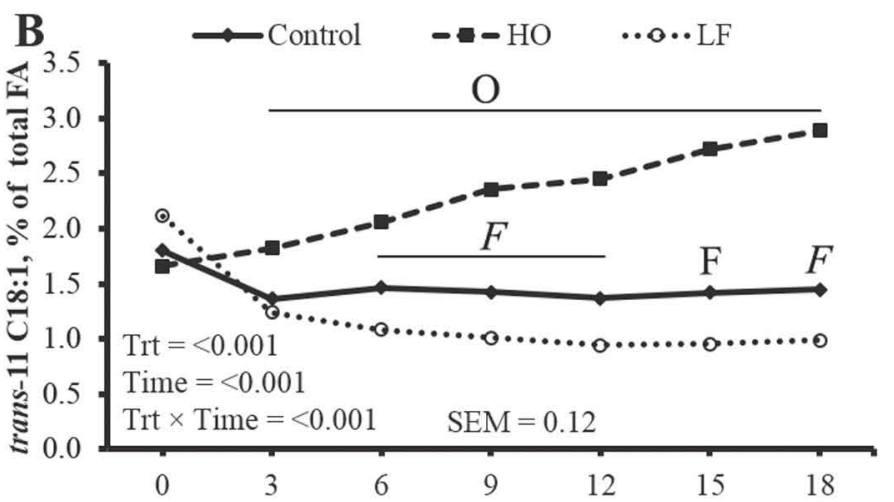

D

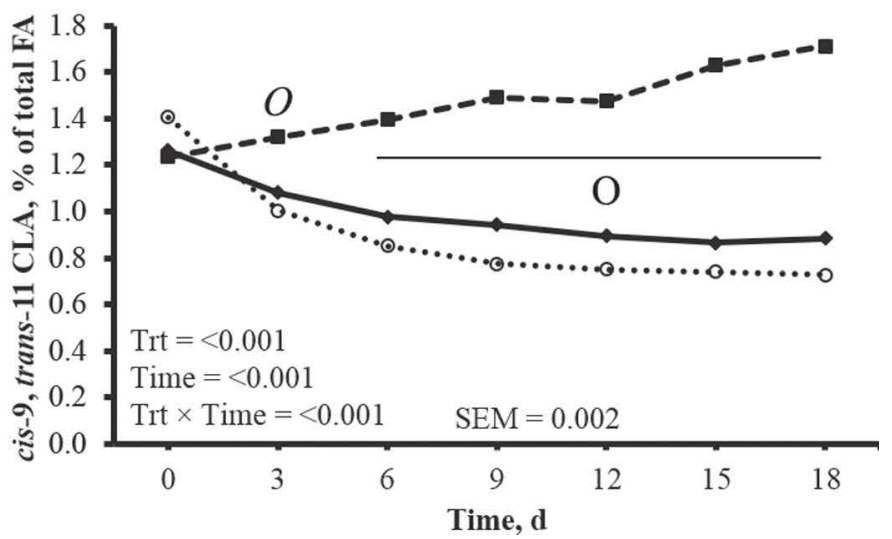

Figure 3. Effect of primarily correcting dietary fiber or unsaturated fatty acid (UFA) concentration on the predominant isomers of the alternate biohydrogenation pathway [trans-10 C18:1 (A) and trans-10,cis-12 CLA (C)] and the predominant isomers of the normal biohydrogenation pathway [trans-11 C18:1 (B) and cis-9,trans-11 CLA (D)] during recovery from milk fat depression. Treatments were a high-fiber, low-UFA diet (control), a diet correcting UFA, but not fiber level (low fiber; LF), and a diet correcting fiber, but not UFA (high oil; HO). Significance of treatment (Trt), time, and the interaction of treatment and time are reported within each figure. Preplanned contrasts tested the difference between control and $\mathrm{LF}(\mathrm{F}=P<0.05, F=P<0.01$, and $\mathrm{f}=P<0.1)$ and between control and $\mathrm{HO}(\mathrm{O}=P<0.05$ and $O=P<0.01)$.

time below pH 5.8 or 5.6. However, an effect of time was observed for all variables. Average rumen $\mathrm{pH}$ rapidly increased during the recovery phase in all treatments, peaked on $\mathrm{d} 3$, and modestly decreased thereafter (Figure 4a). The time below pH 5.8 and 5.6 decreased rapidly, reached near a nadir on d 3, and progressively increased from d 3 to 18 in all treatments (Figure 4b and data not shown, respectively).

\section{Ruminal Microbes}

The LF diet decreased the relative abundance of Fibrobacter succinogenes and tended to decrease $R u$ minoccus albus, whereas HO decreased Megasphaera elsdenii (Table 4; Figure 5). A treatment by time interaction was observed for $S$. bovis $(P<0.05$; Table 4$)$. Streptococcus bovis was increased less than $50 \%$ on d 6 in LF compared with control and tended to be higher on d 9 and 15. However, S. bovis was increased 2 to 5 fold from d 3 to 6 of recovery by $\mathrm{HO}$ compared with control.

There was an effect of time on the relative abundance of all microbial groups analyzed during recovery from milk fat depression $(P<0.05$; Table 4$)$. During recovery M. elsdenii, Selenomonas ruminantium, and Prevotella bryantii were decreased in all treatments and $R$. albus, F. succinogenes, Butyrivibrio/pseudobutyrivibrio, Butyrovibrio hungatei, total fungi, and ciliated protozoa were increased during recovery in all treatments (Figure 5 and 6; Supplemental Figures S3 to S5; http:// dx.doi.org/10.3168/jds.2014-8990).

\section{DISCUSSION}

Alteration of ruminal $\mathrm{BH}$ results in classical dietinduced MFD and can be induced by feeding highconcentrate, low-fiber diets (e.g., Peterson et al., 2003); low-fiber, high-oil diets (e.g., Harvatine and Bauman, 
2006); or high-fiber, high-oil diets (e.g., AlZahal et al., 2008). In the present study, cows were fed a low-fiber, high-UFA diet for $10 \mathrm{~d}$ to induce MFD. Diet UFA were increased using a combination of rapidly available FA from soybean oil and more slowly available FA from roasted soybeans. The predominant FA increased was C18:2, although C18:1 and C18:3 also increased. This short-term treatment reduced milk fat concentration by approximately half of the $50 \%$ maximal decrease possible (Bauman and Griinari, 2001), resulted in induction of the fundamental aspects of diet-induced MFD, and provided an experimental model to investigate recovery from the primary causative mechanisms.

In the present study, milk fat concentration before induction and after recovery was lower than typically observed in Holstein cow herds. However, the high-producing cows used in the experiment were expected to be lower in milk fat concentration (Rico et al., 2014c), and trans isomer concentration indicated a modest presence
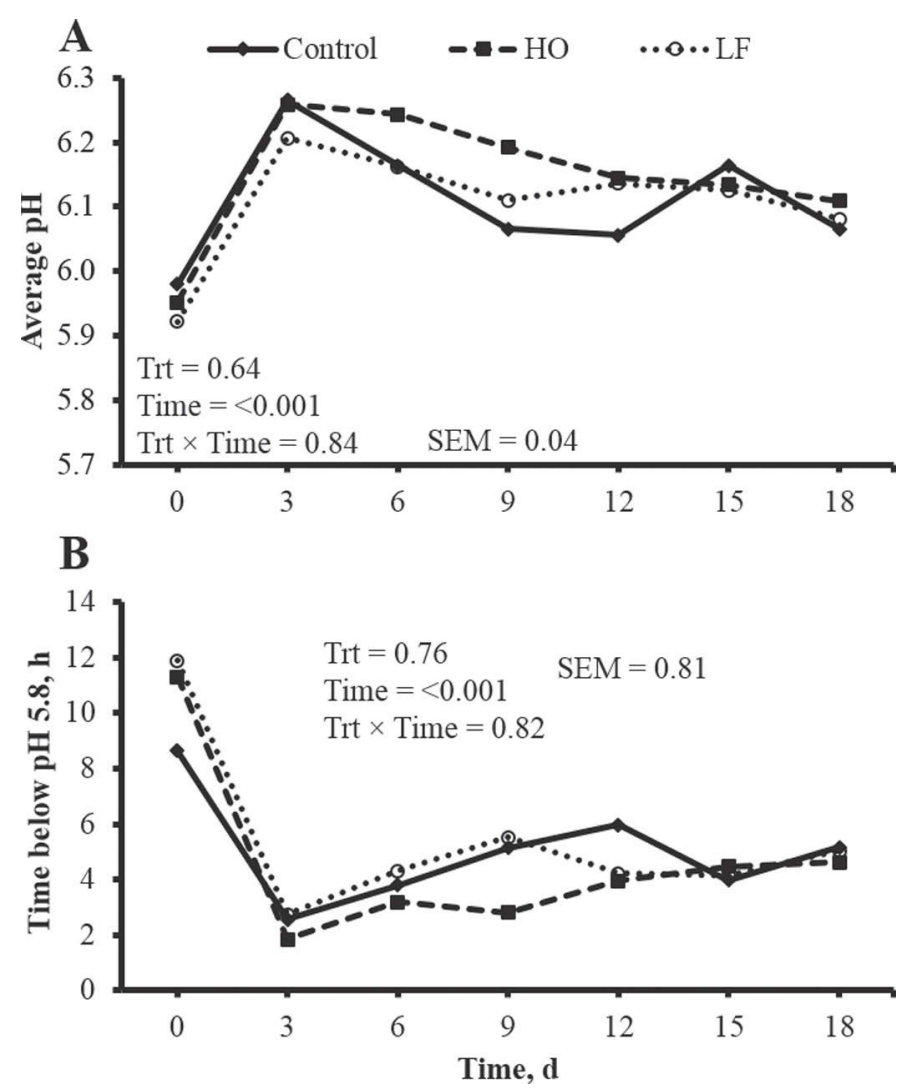

Figure 4. Effect of primarily correcting dietary fiber or unsaturated fatty acid (UFA) concentration on average $\mathrm{pH}(\mathrm{A})$ and time below pH 5.8 (B). Treatments were a high-fiber, low-UFA diet (control), a diet correcting UFA, but not fiber level (low fiber; LF), and a diet correcting fiber, but not UFA (high oil; HO). Significance of treatment (Trt), time, and the interaction of treatment and time are reported within each figure. of alternate $\mathrm{BH}$ intermediates by the end of the recovery phase, suggesting some degree of MFD. Importantly, the objective of the current experiment was to investigate the role of individual diet components on the rate of recovery, which does not require maximal induction nor complete recovery of diet-induced MFD. We have previously observed similar timing of recovery between experiments with varying levels of milk fat (Rico and Harvatine, 2013; Rico et al., 2014a,b).

The induction diet is representative of a high-fermentability, high-UFA diet sometimes unknowingly fed on farms due to changes in forage DM, nutrient composition, and mixing errors, which lead to diet-induced MFD. Additionally, it is also representative of smaller decreases in milk fat observed when diets are marginally high in UFA or fermentability. A short-term induction period was selected because it represents the causative factors of diet-induced MFD and low milk fat is normally rapidly recognized on farms. Longer induction periods may actually result in secondary adaptations and cloud the investigation of the primary mechanisms.

The recovery diets in the current experiment were designed relative to each other and not the MFD induction diet, which was simply used to achieve short-term diet-induced MFD. The control diet corrected both fermentability and UFA level, the HO diet predominantly corrected fermentability while maintaining high UFA, whereas the LF diet predominantly corrected UFA level while maintaining high fermentability. The recovery diets were selected to represent applicable diets that may be fed and that are expected to provide at least partial recovery from MFD. Diets balanced relative to the induction diet may have failed to provide recovery and may not have represented applicable diets. Importantly, a key aspect of the experiment focuses on the time course of recovery with diets differing in fermentability and UFA. Correction of UFA was achieved in the control diet by the removal of soybean oil and substitution of expeller soybean meal for whole roasted soybeans; diet fermentability was corrected by increasing dietary NDF 5.9 percentage units, which reduced starch by 7 percentage units (corn grain substituted by forages). Compared with the control, the effect of dietary fat was tested by increasing total FA and $\mathrm{C} 18: 2$ by 2.4 and 1.34 percentage units (DM basis), respectively, in the HO diet. The effect of fermentability was tested by a forage-to-grain substitution that decreased dietary NDF 3.4\% units (DM basis) in LF relative to control.

The treatments were selected to represent substantially different, but real-world applicable diets. Altered ruminal biohydrogenation is a result of the rumen environment, carbohydrate and FA profile and availability, and many complex interactions (Bauman and Griinari, 
Table 4. Effect of primarily correcting dietary fiber or unsaturated fatty acid (UFA) concentration on the abundance of select ruminal microbes during recovery from diet induced milk fat depression in monensin supplemented diets

\begin{tabular}{|c|c|c|c|c|c|c|c|}
\hline \multirow[b]{2}{*}{ Item, ${ }^{1} \%$ of total bacteria } & \multicolumn{3}{|c|}{ Treatment ${ }^{2,3}$} & \multirow[b]{2}{*}{ SEM } & \multicolumn{3}{|c|}{$P$-value ${ }^{4}$} \\
\hline & Control & $\mathrm{HO}$ & $\mathrm{LF}$ & & Trt & Time & Trt $\times$ time \\
\hline Megasphaera elsdenii & 0.020 & $0.009^{* *}$ & 0.013 & 0.009 & 0.12 & $<0.01$ & 0.15 \\
\hline Selenomonas ruminantium & 0.530 & 0.463 & 0.573 & 0.054 & 0.07 & $<0.01$ & 0.76 \\
\hline \multicolumn{8}{|l|}{ Fibrolytic } \\
\hline Ruminococcus albus & 0.025 & 0.028 & $0.019 \dagger$ & 0.037 & 0.06 & $<0.01$ & 0.61 \\
\hline \multicolumn{8}{|l|}{ Amylolytic } \\
\hline Streptococcus bovis & 0.0005 & $0.0024^{* *}$ & $0.0008^{*}$ & 0.0006 & $<0.01$ & $<0.01$ & $<0.01$ \\
\hline Prevotella bryantii & 0.247 & 0.234 & 0.271 & 0.355 & 0.51 & $<0.01$ & 0.19 \\
\hline \multicolumn{8}{|l|}{ Trans-11 C18:1-producing } \\
\hline Butyrivibrio/Pseudobutyrivibrio & 0.314 & 0.341 & 0.306 & 0.398 & 0.74 & $<0.01$ & 0.69 \\
\hline Butyrivibrio hungatei & 0.0216 & 0.0220 & 0.0193 & 0.0259 & 0.76 & 0.02 & 0.60 \\
\hline Total fungi & 0.237 & 0.299 & 0.214 & 0.057 & 0.21 & $<0.01$ & 0.53 \\
\hline
\end{tabular}

${ }^{1}$ Relative abundance (\% of target gene relative to total bacterial 16S rDNA).

${ }^{2}$ Treatments during recovery from diet induced milk fat depression: control = high-fiber, low-oil diet; HO = high-fiber, high-oil diet; LF $=$ lowfiber, low-oil diet.

${ }^{3}$ Preplanned contrasts tested the difference between control and LF $(* P<0.05, \dagger P<0.1)$, and between control and HO (** $P<0.01$ ).

${ }^{4}$ Trt $=$ treatment effect; Time $=$ effect of time; and Trt $\times$ time $=$ treatment by time interaction.

${ }^{5}$ Data standardized to average of all treatments on $\mathrm{d} 0$ of recovery.

2001; Lourenço et al., 2010). It is important to recognize that treatments are expected to have an effect on the rumen environment, microbial populations, and amount of substrate available for biohydrogenation.

All recovery diets contained higher NDF than the induction diet, which may explain the initial reduction in intake at the start of the recovery phase. The LF diet was lower in NDF and forage NDF than the control diet, and a change in DMI is expected depending on ruminal fill and energy balance (Allen, 2000). Rumen $\mathrm{pH}$ did not differ between treatments. However, abundance of $R$. albus and $F$. succinogenes was moderately lower in LF, reflecting the negative effect of the more fermentable diet on fibrolytic bacteria. Similarly, the lower fermentability in the recovery diets relative to the induction phase was reflected by the reductions in lactate using bacteria Megasphaera elsdenii and $S$. ruminantium (Counotte et al., 1981), and in amylolytic bacteria such as $P$. bryantii. Dry matter intake was unaffected by $\mathrm{HO}$ compared with control, despite the higher dietary oil concentration and energy density in the HO diet. This difference may have been too small to observe a change in intake, and although high UFA concentrations in the diet are commonly expected to impair fiber digestibility through negative effects on fibrolytic bacteria (Jenkins, 1993; Maia et al., 2007), effects were not observed on $R$. albus, F. succinogenes, or Prevotella ruminicola in the current experiment. $\mathrm{Ru}-$ men $\mathrm{pH}$ recovered rapidly in all treatments, but milk trans isomer profiles clearly indicated altered fermentation with $\mathrm{HO}$, which could be the result of microbial populations shifts in the rumen. Unsaturated FA are known to have direct toxic effects on ruminal bacteria (Maia et al., 2010, 2007), resulting in a shift in the ruminal microbial population (Lourenço et al., 2010). Interestingly, $S$. bovis abundance was progressively increased by $\mathrm{HO}$ and was increased to a lesser extent by LF relative to control, suggesting a positive effect of UFA on this species, perhaps related to its moderately higher tolerance to UFA compared with other amylolytic bacteria such as $P$. bryantii (Maia et al., 2007).

Previously, we conducted a high-frequency time course and reported that correction of both dietary fiber and UFA concentration recovered milk fat concentration and yield within 19 d (Rico and Harvatine, 2013). In the current study, a similar progressive increase in milk fat yield was observed over $18 \mathrm{~d}$ by minimizing UFA or increasing fiber and minimizing UFA. Milk fat concentration was lower in the LF diet than control from $d$ 12 to 18 ; however, milk yield was numerically increased during the same period, resulting in no change in milk fat yield. Differences in the concentration and yield of de novo-synthesized FA was minimal between control and LF, and both followed a similar trend, increasing progressively during recovery from diet-induced MFD and plateauing around d 15. Interestingly, trans-10 18:1 
and trans-10,cis-12 CLA decreased rapidly in LF during the first $6 \mathrm{~d}$ of recovery, but were higher than control for the remainder of the recovery phase, coinciding with the same period of reduced milk fat concentration suggesting some maintenance of the alternate $\mathrm{BH}$ pathways and inability to biohydrogenate the high level of UFA in the diet.

Although increasing fiber, but not correcting UFA concentration, resulted in lower milk fat yield on d 15 , it was not different from control during the rest of the recovery phase. However, de novo FA concentration and yield did not recover in the HO treatment, which is likely a combined effect of both higher milk trans-10 18:1 and trans-10,cis-12 CLA concentrations in the HO treatment and higher availability of preformed FA, both of which can reduce de novo FA in milk fat (Rico et al., 2014c). Although trans-10 18:1 and trans-10,cis-12 CLA decreased progressively during recovery, they were considerably higher in $\mathrm{HO}$ than control. The progressive increase in milk trans-11 C18:1 and cis-9,trans-11 CLA in HO indicated a gradual return to normal ruminal BH. Long-chain FA are known to decrease de novo-synthesized FA in milk (Drackley et al., 1992). In the current experiment, the concentration of FA in the HO diet was more than 2.1 percentage units higher than control and LF diets, but was 0.5 percentage units lower than the MFD-induction diet and the reduction in intake further decreased absorbed FA. Interestingly, the yield of de novo FA was initially numerically decreased during recovery indicating little effect of the slight reduction in absorbed FA. The observed increase in milk preformed FA yield in the HO group was likely
A.
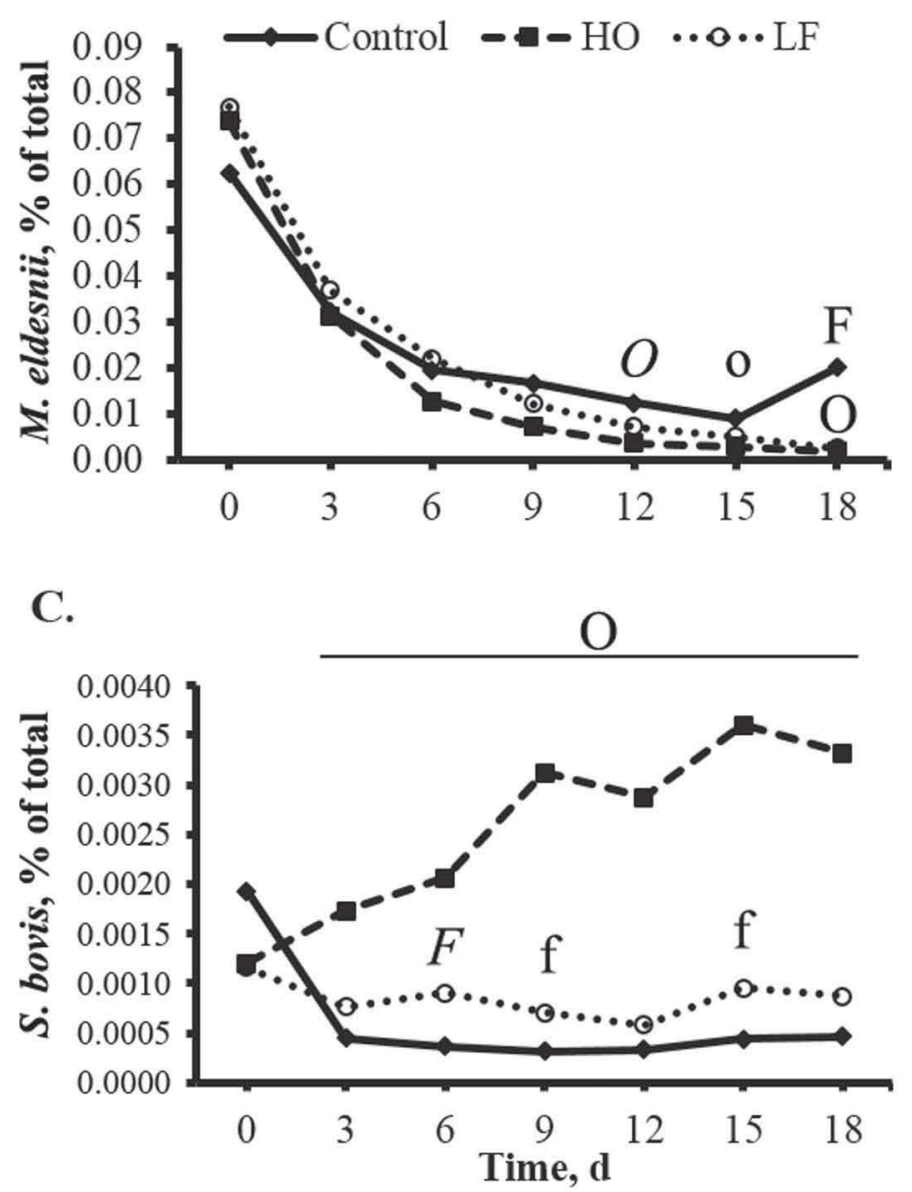

B.



D.

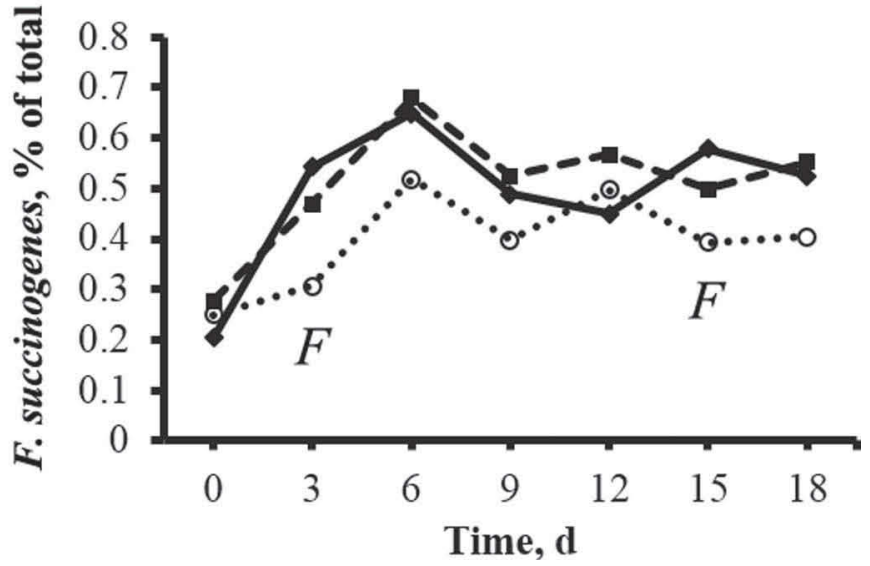

Figure 5. Effect of primarily correcting dietary fiber or unsaturated fatty acid (UFA) concentration on the abundance of Megasphaera elsdenii (A), Ruminococcus albus (B), Streptococcus bovis (C), and Fibrobacter succinogenes (D) expressed as a percent of total bacteria. Treatments were a high-fiber, low-UFA diet (control), a diet correcting UFA, but not fiber level (low fiber; LF), and a diet correcting fiber, but not UFA (high oil; HO). Significance of treatment (Trt), time, and the interaction of treatment and time are reported within each figure. Preplanned contrasts tested the difference between control and $\mathrm{LF}(\mathrm{F}=P<0.05, F=P<0.01$, and $\mathrm{f}=P<0.1)$ and between control and $\mathrm{HO}(\mathrm{O}=P$ $<0.05, O=P<0.01$, and $\mathrm{o}=P<0.1)$. 

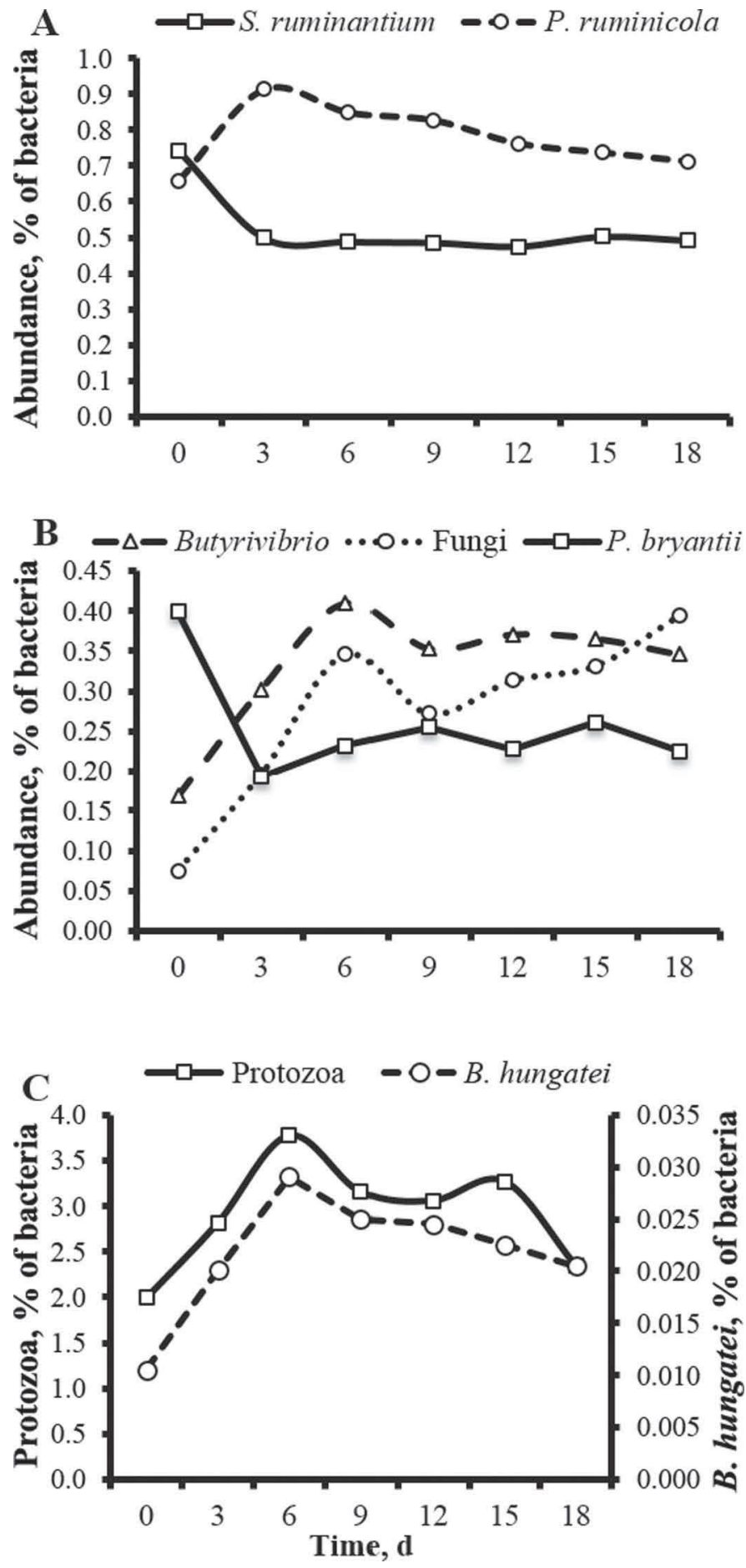

Figure 6. Change in ruminal abundance (\% of total bacteria) of Selenomonas ruminantium and Prevotella ruminicola (A), Butyrivibrio/ Pseudobutyrivibrio, total fungi, and Prevotella bryantii (B), and ciliate protozoa and Butyrivibrio hungatei $(\mathrm{C})$ during recovery from milk fat depression. The effect of time was significant for all species, but no treatment by time interactions ( $P$-values and SEM in Table 4$)$ were noted. The least squares means of time are shown. the result of increased absorbed FA and indicated little inhibition of the uptake of preformed FA in the mammary gland.

Megasphaera elsdenii (YJ4) was reported to be a trans-10,cis-12 CLA producer (Kim et al., 2002); however, in the present experiment, no apparent relationship was noted between trans-10,cis-12 CLA and $M$. elsdenii, similar to other reports (Wallace et al., 2006). In contrast, $S$. bovis was increased by $\mathrm{HO}$, but it is traditionally known as an amylolytic bacteria that produces lactic acid (Russell and Hino, 1985; Cotta, 1988). It is not known to be involved in the formation of trans10,cis-12 CLA, but is associated with the formation of hydroxy-C18 FA (Maia et al., 2007). The Butyrivibrio/ Pseudobutyrivibrio and B. hungateii groups are known for their role in the formation of cis-9,trans-11 CLA and trans-11 C18:1 from LA (Lourenço et al., 2010), and both reached peak concentrations by d 6 of recovery regardless of treatment. Similar recovery trends were observed for fungi and protozoa. Ciliate protozoa are not known to have important roles on ruminal metabolism of LA, but contribute to the ruminal outflow of both cis-9,trans-11 CLA and trans-11 C18:1 (Devillard et al., 2006; Yáñez-Ruiz et al., 2006). Conversely, some species of anaerobic fungi, such as Neocallimastix frontalis, produce cis-9,trans-11 CLA. The major changes in total fungi during recovery highlights the potential for other roles in rumen biohydrogenation.

A 2-phase response previously reported on $\mathrm{BH}$ intermediates during recovery from diet-induced MFD by correction of dietary fiber and UFA (Rico and Harvatine, 2013; Rico et al., 2014b). Briefly, milk concentrations of intermediates in the altered $\mathrm{BH}$ pathway (trans-10 C18:1 and trans-10,cis-12 CLA) decreased during the first phase and presumably represent reestablishment of normal microbial populations. The second phase was characterized by a slight elevation of trans FA in the normal pathway (trans-11 C18:1 and cis-9,trans-11 CLA) suggesting a secondary phase of adaptation in ruminal microbial populations and $\mathrm{BH}$ capacity. In the current experiment, FA in the altered pathway decreased rapidly during the first phase of recovery for control and LF treatments, but the isomers in the normal pathway were not elevated above baseline in a secondary phase. It is possible that monensin supplementation in the current experiment prevented or delayed the second adaptation in $\mathrm{BH}$ intermediates observed previously previous experiments (Rico and Harvatine, 2013; Rico et al., 2014b). Indeed, the major adaptations of ruminal microbes observed in the present experiment occurred during the initial phase of recovery, and no major changes were observed for most taxa after d 6 of recovery. 
Diet-induced MFD is correlated with changes in the rumen environment, microbial populations, and amount and type of FA and carbohydrate substrate available. Low rumen $\mathrm{pH}$ has been classically proposed as a driving factor in the change in the microbial population and rates and pathway of $\mathrm{BH}$, and has been clearly demonstrated in vitro (Choi et al., 2005; Fuentes et al., 2009). Additionally, rumen $\mathrm{pH}$ is correlated with milk fat concentration in vivo (Allen, 1997). However, in the current experiment, rumen $\mathrm{pH}$ was corrected rapidly when fed the recovery diets, but the change in absorbed $\mathrm{BH}$ intermediates occurred progressively in all treatments. Additionally, rumen $\mathrm{pH}$ was corrected in the $\mathrm{HO}$ treatment, but recovery of normal $\mathrm{BH}$ intermediates in milk was inhibited, which could reflect the higher amount of substrate in addition to difference in passage rate and $\mathrm{BH}$ capacity. The lag between improvement in rumen $\mathrm{pH}$ and recovery of normal $\mathrm{BH}$ intermediates may demonstrate the lag required for re-establishment of the microbial populations, or may represent a smaller role of $\mathrm{pH}$ in diet-induced MFD than ruminal UFA load.

\section{CONCLUSIONS}

Decreasing alternate $\mathrm{BH}$ intermediates in milk fat following classical diet-induced MFD can most effectively be achieved through correction of dietary UFA concentration. Although recovery of milk fat yield was not different among treatments, increasing dietary fiber while maintaining a high UFA concentration (4.8\%) resulted in increased trans-10 C18:1 and trans-10,cis-12 CLA, which is associated with classical diet-induced MFD. The high-fermentability diet $(3.4 \%$ lower in $\mathrm{NDF}$ ) also slightly increased these $\mathrm{BH}$ intermediates above control. Overall, milk fat synthesis was rapidly increased by decreasing diet fermentability and UFA concentration, which provides support for focusing on these risk factors when designing strategies to recover from diet-induced MFD.

\section{ACKNOWLEDGMENTS}

Gratitude is expressed to Y. Ying, M. Niu, A. R. Clarke, J. Risser, E. Wambaugh, and H. Stultz (Penn State University, University Park, PA) for technical assistance and to all personnel at the Pennsylvania State University Dairy Cattle Research and Education Center for feeding and continuous care of animals. Real-time PCR was conducted at the Huck Institute Genomics Core Center. The authors also gratefully acknowledge the donation of SoyPLUS and soybean oil by West Central Cooperative (Ralston, IA). This project was funded by Elanco Animal Health (Greenfield, IN). Thoughtful discussion with the Elanco dairy technical service team was also appreciated.

\section{REFERENCES}

Allen, M. S. 1997. Relationship between fermentation acid production in the rumen and the requirement for physically effective fiber. J. Dairy Sci. 80:1447-1462.

Allen, M. S. 2000. Effects of diet on short-term regulation of feed intake by lactating dairy cattle. J. Dairy Sci. 83:1598-1624.

AlZahal, O., N. E. Odongo, T. Mutsvangwa, M. M. Or-Rashid, T. F. Duffield, R. Bagg, P. Dick, G. Vessie, and B. W. McBride. 2008. Effects of monensin and dietary soybean oil on milk fat percentage and milk fatty acid profile in lactating dairy cows. J. Dairy Sci. 91:1166-1174.

Bauman, D. E., and J. M. Griinari. 2001. Regulation and nutritional manipulation of milk fat: Low-fat milk syndrome. Livest. Prod. Sci. 70:15-29.

Choi, N.-J., J. Y. Imm, S. Oh, B.-C. Kim, H.-J. Hwang, and Y. J. Kim. 2005. Effect of $\mathrm{pH}$ and oxygen on conjugated linoleic acid (CLA) production by mixed rumen bacteria from cows fed high concentrate and high forage diets. Anim. Feed Sci. Technol. 123124:643-653.

Cotta, M. A. 1988. Amylolytic activity of selected species of ruminal bacteria. Appl. Environ. Microbiol. 54:772-776.

Counotte, G. H., R. A. Prins, R. H. Janssen, and M. J. Debie. 1981. Role of Megasphaera elsdenii in the fermentation of DL-[2-C]lactate in the rumen of dairy cattle. Appl. Environ. Microbiol. 42:649-655.

Devillard, E., F. M. McIntosh, C. J. Newbold, and R. J. Wallace. 2006. Rumen ciliate protozoa contain high concentrations of conjugated linoleic acids and vaccenic acid, yet do not hydrogenate linoleic acid or desaturate stearic acid. Br. J. Nutr. 96:697-704.

Drackley, J. K., T. H. Klusmeyer, A. M. Trusk, and J. H. Clark. 1992. Infusion of long-chain fatty acids varying in saturation and chain length into the abomasum of lactating dairy cows. J. Dairy Sci. 75:1517-1526.

Duffield, T. F., A. R. Rabiee, and I. J. Lean. 2008. A meta-analysis of the impact of monensin in lactating dairy cattle. Part 2. Production effects. J. Dairy Sci. 91:1347-1360.

Fritsche, J., R. Rickert, H. Steinhart, M. P. Yurawecz, M. M. Mossoba, N. Sehat, J. A. G. Roach, J. K. G. Kramer, and Y. Ku. 1999. Conjugated linoleic acid (CLA) isomers: Formation, analysis, amounts in foods, and dietary intake. Europ. J. Lipid Sci. Technol. 101:272-276.

Fuentes, M. C., S. Calsamiglia, P. W. Cardozo, and B. Vlaeminck. 2009. Effect of $\mathrm{pH}$ and level of concentrate in the diet on the production of biohydrogenation intermediates in a dual-flow continuous culture. J. Dairy Sci. 92:4456-4466.

Harvatine, K. J., and D. E. Bauman. 2006. SREBP1 and thyroid hormone responsive spot $14(\mathrm{~S} 14)$ are involved in the regulation of bovine mammary lipid synthesis during diet-induced milk fat depression and treatment with CLA. J. Nutr. 136:2468-2474.

Harvatine, K. J., Y. R. Boisclair, and D. E. Bauman. 2009. Recent advances in the regulation of milk fat synthesis. Animal 3:40-54.

He, M., K. L. Perfield, H. B. Green, and L. E. Armentano. 2012. Effect of dietary fat blend enriched in oleic or linoleic acid and monensin supplementation on dairy cattle performance, milk fatty acid profiles, and milk fat depression. J. Dairy Sci. 95:1447-1461.

Jenkins, T. C. 1993. Lipid metabolism in the rumen. J. Dairy Sci. 76:3851-3863.

Kim, Y. J., R. H. Liu, J. L. Rychlik, and J. B. Russell. 2002. The enrichment of a ruminal bacterium (Megasphaera elsdenii YJ-4) that produces the trans-10,cis-12 isomer of conjugated linoleic acid. J. Appl. Microbiol. 92:976-982.

Lourenço, M., E. Ramos-Morales, and R. J. Wallace. 2010. The role of microbes in rumen lipolysis and biohydrogenation and their manipulation. Animal 4:1008-1023. 
Maia, M. R., L. C. Chaudhary, C. S. Bestwick, A. J. Richardson, N. McKain, T. R. Larson, I. A. Graham, and R. J. Wallace. 2010. Toxicity of unsaturated fatty acids to the biohydrogenating ruminal bacterium, Butyrivibrio fibrisolvens. BMC Microbiol. 10:52.

Maia, M. R., L. C. Chaudhary, L. Figueres, and R. J. Wallace. 2007. Metabolism of polyunsaturated fatty acids and their toxicity to the microflora of the rumen. Antonie van Leeuwenhoek 91:303-314.

Peterson, D. G., E. A. Matitashvili, and D. E. Bauman. 2003. Diet-induced milk fat depression in dairy cows results in increased trans10,cis-12 CLA in milk fat and coordinated suppression of mRNA abundance for mammary enzymes involved in milk fat synthesis. J. Nutr. 133:3098-3102.

Rico, D. E., and K. J. Harvatine. 2013. Induction of and recovery from milk fat depression occurs progressively in dairy cows switched between diets that differ in fiber and oil concentration. J. Dairy Sci. 96:6621-6630.

Rico, D. E., A. W. Holloway, and K. J. Harvatine. 2014a. Effect of monensin on recovery from diet-induced milk fat depression. J. Dairy Sci. 97:2376-2386.

Rico, D. E., Y. Ying, A. R. Clarke, and K. J. Harvatine. 2014b. The effect of rumen digesta inoculation on the time course of recovery from classical diet-induced milk fat depression in dairy cows. J. Dairy Sci. 97:3752-3760.

Rico, D. E., Y. Ying, and K. J. Harvatine. 2014c. Effect of a highpalmitic acid fat supplement on milk production and apparent total-tract digestibility in high- and low-milk yield dairy cows. J. Dairy Sci. 97:3739-3751.

Russell, J. R., and T. Hino. 1985. Regulation of lactate production in Streptococcus bovis: A spiraling effect that contributes to rumen acidosis. J. Dairy Sci. 68:1712-1721.

Wallace, R. J., L. C. Chaudhary, N. McKain, N. R. McEwan, A. J. Richardson, P. E. Vercoe, N. D. Walker, and D. Paillard. 2006. Clostridium proteoclasticum: A ruminal bacterium that forms stearic acid from linoleic acid. FEMS Microbiol. Lett. 265:195-201.

Weimer, P. J., D. M. Stevenson, and D. R. Mertens. 2010. Shifts in bacterial community composition in the rumen of lactating dairy cows under milk fat-depressing conditions. J. Dairy Sci. 93:265278

Yáñez-Ruiz, D. R., N. D. Scollan, R. J. Merry, and C. J. Newbold. 2006. Contribution of rumen protozoa to duodenal flow of nitrogen, conjugated linoleic acid and vaccenic acid in steers fed silages differing in their water-soluble carbohydrate content. Br. J. Nutr. 96:861-869.

Ying, Y., L. W. Rottman, A. R. Clarke, and K. J. Harvatine. 2015. The effects of feeding regimens that teed two rations over the day on production and rumen fermentation in dairy cows. J. Dairy Sci. 98:4685-4698

Yu, Z., and M. Morrison. 2004. Improved extraction of PCR-quality community DNA from digesta and fecal samples. Biotechniques $36: 808-812$. 